\title{
Lingual deficits in neurotrophin double knockout mice
}

\author{
IRINA V. NOSRAT ${ }^{1}$, KARIN AGERMAN ${ }^{2}$, ANDREA MARINESCU ${ }^{1}$, \\ PATRIK ERNFORS ${ }^{2}$ and CHRISTOPHER A. NOSRAT ${ }^{1, *}$ \\ ${ }^{1}$ Laboratory of Oral Neurobiology, Department of Biological and Materials Sciences, School of Dentistry, University of Michigan, \\ Ann Arbor, MI 48109; ${ }^{2}$ Unit of Molecular Neurobiology, MBB, Karolinska Institutet, 17177 Stockholm, Sweden \\ nosrat@umich.edu
}

Received 18 December 2004; revised 25 January 2005; accepted 5 June 2005

\begin{abstract}
Brain-derived neurotrophic factor (BDNF) and Neurotrophin 3 (NT-3) are members of the neurotrophin family and are expressed in the developing and adult tongue papillae. BDNF null-mutated mice exhibit specific impairments related to innervation and development of the gustatory system while NT-3 null mice have deficits in their lingual somatosensory innervation. To further evaluate the functional specificity of these neurotrophins in the peripheral gustatory system, we generated double BDNF/NT-3 knockout mice and compared the phenotype to $\mathrm{BDNF}^{-1-}$ and wild-type mice. Taste papillae morphology was severely distorted in $\mathrm{BDNF}^{-/-} x \mathrm{NT}_{-} 3^{-/-}$mice compared to single $\mathrm{BDNF}^{-/-}$and wild-type mice. The deficits were found throughout the tongue and all gustatory papillae. There was a significant loss of fungiform papillae and the papillae were smaller in size compared to $\mathrm{BDNF}^{-/-}$and wild-type mice. Circumvallate papillae in the double knockouts were smaller and did not contain any intraepithelial nerve fibers. $\mathrm{BDNF}^{-/-} x \mathrm{NT}_{-} 3^{-/-}$mice exhibited additive losses in both somatosensory and gustatory innervation indicating that BDNF and NT-3 exert specific roles in the innervation of the tongue. However, the additional loss of fungiform papillae and taste buds in $\mathrm{BDNF}^{-/-} x \mathrm{NT}^{-3^{-/}}$mice compared to single BDNF knockout mice indicate a synergistic functional role for both BDNF-dependent gustatory and NT-3-dependent somatosensory innervations in taste bud and taste papillae innervation and development.
\end{abstract}

\section{Introduction}

Specialized epithelial cells (Barlow \& Northcutt, 1995; Stone et al., 1995) that are located in specialized sensory organs, the taste buds, give mammals the ability to taste sweet, bitter, sour, salt, and umami compounds (Lindemann, 2001). Taste buds are found in palate, tongue, larynx, etc. and are innervated by specific branches of the 7 th, 9th, and 10th cranial nerves. Taste buds on the dorsal surface of the tongue in mammals are found in special structures called gustatory papillae; namely fungiform, foliate and circumvallate papillae. Fungiform papillae cover the anterior surface of the tongue. In rodents, there is generally one taste bud embedded in the epithelium of the apical portion of each papilla. Many taste buds are also embedded in the epithelium of the foliate and circumvallate papillae.

The peripheral taste organ is an excellent sensory system for characterization of the interactions between the target tissues and the nervous system. Development and maintenance of the gustatory sensory organs, the taste buds, require appropriate connections with gustatory nerve fibers that innervate them. It has been shown that the development and innervation of taste buds, as well as maintenance of the papillae housing them, are related to appropriate neurotrophin signaling (see Farbman, 2003). In a classical study from Farbman's Laboratory (Farbman \& Mbiene, 1991), it was suggested that neurotrophic factors might be involved in the establishment of the innervation of gustatory papillae and taste buds. Our studies of the gustatory system established that BDNF and NT-3 transcripts are expressed in the developing and adult rodent and human tongues (Nosrat \& Olson, 1995, 1998; Nosrat et al., 1996, 1997, 2000; Nosrat, 1998). Using different approaches and different species, the presence of these neurotrophins in gustatory papillae and taste buds has been confirmed (Uchida et al., 2003; Yee et al., 2003; Ganchrow et al., 2003a, 2003b; Fan et al., 2004).

BDNF transcripts are associated with the developing gustatory epithelium and adult taste buds and

\footnotetext{
* To whom correspondence should be addressed.
} 
NT-3 transcripts with the surrounding lingual epithelium. BDNF transcripts are expressed in the developing gustatory epithelium before the nerve fibers have reached and penetrated the epithelium in both rodents and humans, indicating a prespecialization of the gustatory epithelium. NT-3 mRNA is not expressed in the taste bud proper in rodents. Based on these anatomical findings, we hypothesized that BDNF might be related to the gustatory innervation, whereas NT-3 would play a role for the lingual somatosensory innervation. It was subsequently shown that BDNF null-mutated mice exhibit specific impairments related to the innervation and development of the gustatory system, while NT-3 null mice have deficits in their lingual somatosensory innervation (Nosrat et al., 1997; Zhang et al., 1997). BDNF knockout mice had malformed papillae and far fewer taste buds than wild-type mice (Nosrat et al., 1997; Zhang et al., 1997; Mistretta et al., 1999). Experiments utilizing transgenic technology, have shown that BDNF and neurotrophin 4 (NT-4) attract and support innervation of lingual targets that ectopically produce them (Ringstedt et al., 1999; Krimm et al., 2001) indicating that tissue specific expression of BDNF is important for appropriate gustatory innervation and connectivity in the tongue (Ringstedt et al., 1999; Krimm et al., 2001).

In the present study, we took advantage of loss-offunction in neurotrophin knockout mice to understand the involvement of BDNF and NT-3 in the innervation and development of the peripheral taste system. Based on the distinct gustatory and somatosensory deficits that are observed respectively in BDNF and NT-3 knockout mice, we hypothesized that deficits in $\mathrm{BDNF}^{-/-} x \mathrm{NT}-3^{-/-}$mice would be additive, i.e., a sum of both gustatory and somatosensory deficits. By analyzing and comparing the phenotype to BDNF knockout mice, the possible interactions between BDNF and NT-3 were examined.

\section{Materials and methods}

BDNF (Ernfors et al., 1994a) and NT-3 (Ernfors et al., 1994b) heterozygous mice were crossbred to generate BDNF/NT-3 heterozygous mice. One allele for each gene is nullmutated in the heterozygous mice and these mice are viable and reproduce. By crossbreeding the $\mathrm{BDNF}^{+/-} x \mathrm{NT}-3^{+/-}$mice, homozygous $\mathrm{BDNF}^{-/-} x \mathrm{NT}-3^{-1-}$ mice were generated. We used a PCR-based genotyping approach to identify the transgenic mice. The homozygous double knockout mice die shortly after birth and therefore all mice used in this study were analyzed on the day of birth (postnatal day 0, P0). Procedures were approved by the Institutional Animal User Committee (IAUC) at the University of Michigan, and the local Animal Research Committee of Stockholm, Sweden. P0 pups were euthanized by decapitation and tissue samples were used to genotype the mice as described previously (Ernfors et al., 1995). Tongues or whole heads were immersion fixed overnight in $4 \%$ paraformaldehyde (PFA) in phosphate buffered saline (PBS) at $4{ }^{\circ} \mathrm{C}$. Tongues that were used for scanning electron microscopy were kept in the fixative until processing.

\section{SCANNING ELECTRON MICROSCOPY}

Upon use, tongues were rinsed in PBS and dehydrated in a graded series of ethanol that was exchanged during three subsequent washes in hexamethyldisilazane (HMDS) (Mistretta et al., 2003; Mbiene et al., 1997; Agerman et al., 2003). Residual HMDS was allowed to evaporate in a fume hood overnight. The tongues were then mounted on stubs, lightly sputtercoated with gold/palladium, and studied in a scanning electron microscope (Amray 1000-B, Bedford, MA) at $10 \mathrm{kV}$.

\section{IMMUNOHISTOCHEMISTRY}

Tissue that had already been immersion fixed was cryopreserved in $10 \%$ or $20 \%$ sucrose in PBS overnight, cryosectioned (14 $\mu \mathrm{m}$, frontal sections, Microme cryostat, Richard Allan Scientific, MI) and mounted on slides. Antibodies against protein gene product 9.5 (PGP, Biogenesis LTD., Great Britain and Chemicon, Temecula, CA) were used (diluted 1:400) to maximize visualization of the innervation apparatus of the tongue. Cyanine 2 coupled secondary antibodies were used (Jackson ImmunoResearch Laboratories, West Grove, PA). Procedures for immunohistochemistry were according to Hökfelt et al. (1973). Sections were analyzed using epifluorescence microscopy (Nikon Eclipse E600, Mager Scientific, Ann Arbor, MI). Selected areas were documented using confocal microscopy (Bio-Rad Radiance 2000, Hercules, CA).

To estimate a relative number of fungiform papillae, the papillae were counted on every fourth tissue section on serially sectioned tongue tissue. To measure the diameter of the fungiform papillae, the papillae were photographed and the digital images were imported into Photoshop software (Adobe Photoshop 7, Adobe Systems Incorporated, San Jose, CA). There were fewer fungiform papillae remaining in the posterior parts of the tongues in the transgenic mice, and therefore the measurements were all done on anteriorly located fungiform papillae (10 papillae/mouse, $n=3$ ). The widest portion of the papillae was measured representing the diameter of the papillae (see Fig. 2A). The circumvallate papillae were photographed midway on frontal sections. We defined the midway based on the number of tissue sections containing the papilla and the section in the middle was selected for analysis and was photographed. The vertical and horizontal dimensions of each papilla were measured. The horizontal measure was the distance between two points on each side of the papilla on the basal lamina of the outer trench epithelium. The vertical dimension was the distance between the highest point of the top surface epithelium to a line connecting the bottom of the trenches to each other. Multiplying the vertical and horizontal measures gave a relative size of the papillae (see Fig. 3). All measures were entered into GraphPad Instat (GraphPad Software, Inc., San Diego, CA) software for statistical analysis (ANOVA and Bonferroni post-hoc test) between the groups. 

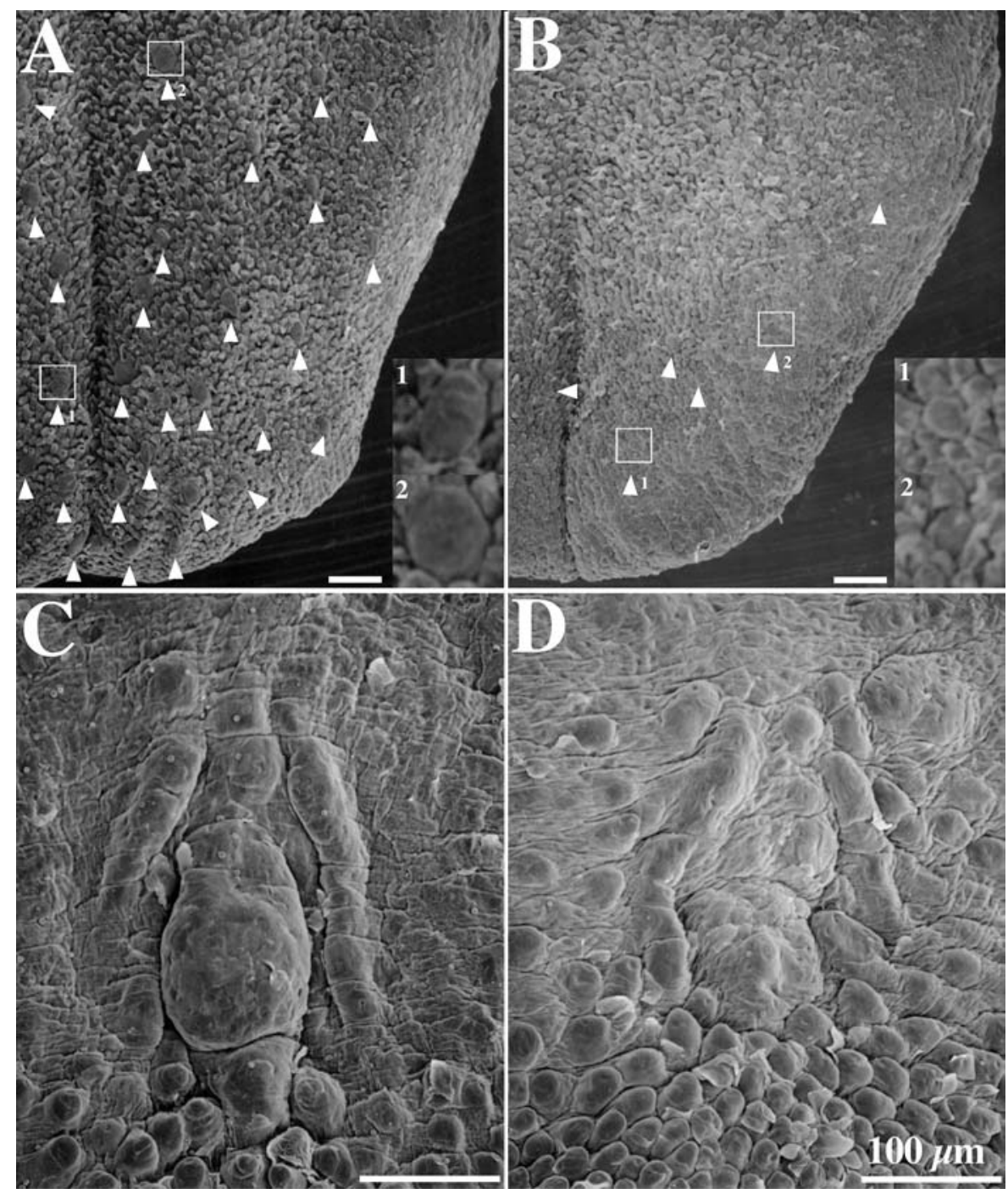

Fig. 1. Scanning electron micrographs of the dorsal surface of the tongue visualizing tongue papillae morphology in new-born wild-type and $\mathrm{BDNF}^{-1-} x \mathrm{NT}^{-3^{-/-}}$mice. Scale bars represent $100 \mu \mathrm{m}$ in Figures A-D. (A) Many fungiform papillae (arrowheads) are observed on the anterior part of the tongue in wild-type mice. Boxed areas 1 and 2 are examples of wild-type papillae and are shown at higher magnification in the lower right corner of Fig. 1A. (B) Only few small-size papillae are observed on the dorsal surface of the tongue in $\mathrm{BDNF}^{-/-} x \mathrm{NT}^{-3^{-/-}}$mice. Boxed areas 1 and 2 are examples of fungiform papillae in $\mathrm{BDNF}^{-/-} x \mathrm{NT}^{-}$ $3^{-1-}$ mice and are shown at higher magnification in the lower right corner of Fig. 1B. (C) Circumvallate papilla in wild-type mice is well-developed. The papilla is dome-shaped and the trenches are visible on each side. (D) Circumvallate papilla morphology is distorted in $\mathrm{BDNF}^{-/-} x \mathrm{NT}-3^{-/-}$mice. The papillae and its trenches appear underdeveloped in $\mathrm{BDNF}^{-/-} x \mathrm{NT}^{-3^{-/-}}$ mice.

\section{Results}

\section{FUNGIFORM PAPILLAE}

Many fungiform papillae were observed in wild-type mice and they covered the entire portion of the anterior tongue (Fig. 1A). Fungiform papillae were observed in the posterior portion of the tongue (posterior to the intermolar eminence). Innervation of the papillae was assessed using immunohistochemistry to protein gene product 9.5 (PGP). PGP is a useful marker of fine nerve fibers. PGP antibodies label a subset of taste cells (see
Takeda et al., 2004), but since our focus in the present study was on the pattern of innervation, it did not impose any problems. Fungiform papillae in newborn wild-type mice were richly innervated (Fig. 2A and B). Many nerve fibers entered the papillae core and ramified either into the taste buds or into the surrounding epithelium. Both perigemmal and intragemmal innervation components of the papillae were easily recognizable (see Fig. 2B). The papillae were large (Fig. 2A and B) and had a large diameter ( $39 \mu \mathrm{m} \pm 0.5 \mathrm{SEM})$. In newborn $\mathrm{BDNF}^{-/-}$mice (Fig. 2C and D), the innervation 

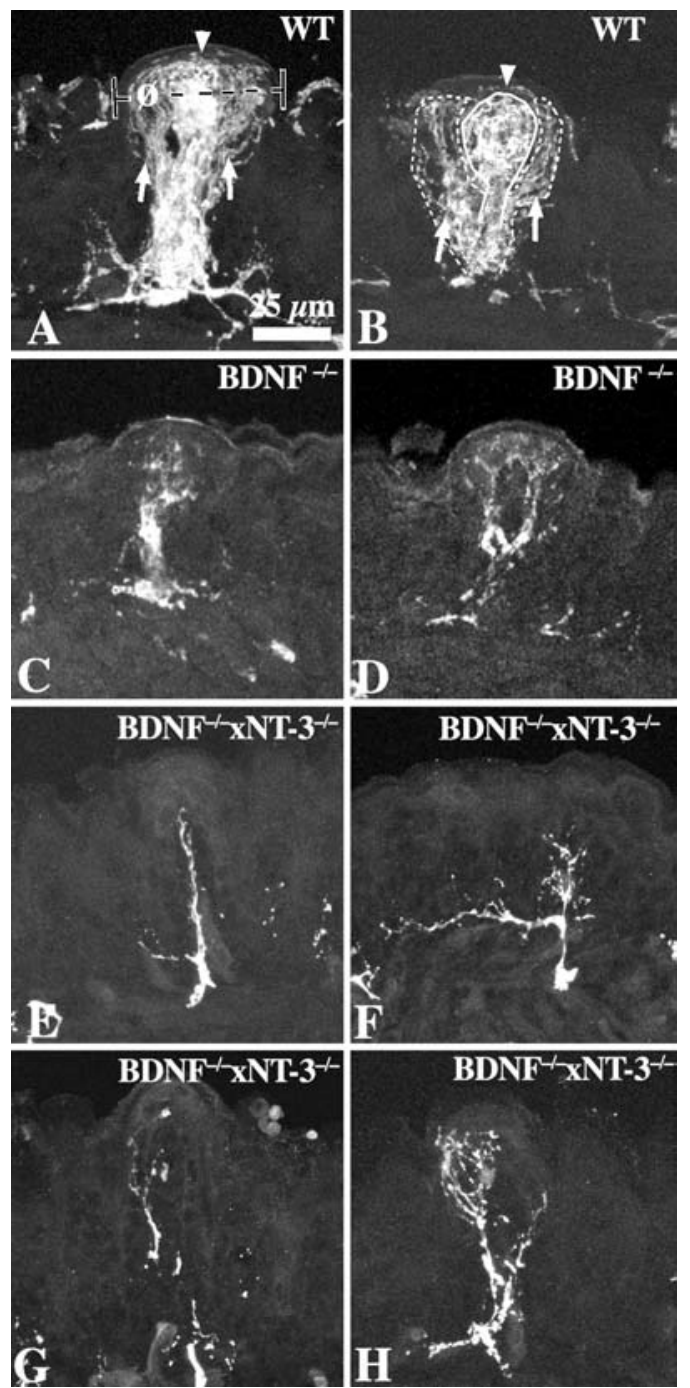

Fig. 2. (A-H) Examples of representative fungiform papillae in newborn wild-type $\left(\mathrm{A}, \mathrm{B}, \mathrm{BDNF}^{-1-}(\mathrm{C}, \mathrm{D})\right.$, and $\mathrm{BDNF}^{-1-} x \mathrm{NT}^{-3^{-/-}}(\mathrm{E}-\mathrm{H})$ mice. Immunohistochemistry to PGP 9.5 was used to stain nerve fibers. Scale bar in A represents $25 \mu \mathrm{m}$ and applies to Fig. A-H. (A and B) In wildtype mice, fungiform papillae and fungiform taste buds are highly innervated and both intragemmal and perigemmal components of the innervations are clearly visible. The widest portion of the papillae was measured representing the diameter of the papillae $(\emptyset)$. The fungiform taste bud and its intragemmal innervation are marked with arrowheads and perigemmal innervation with arrows in Fig 2A and B. The gross distinction of areas that receive perigemmal innervation (dashed line) and intragemmal innervation (unbroken line) are also marked in Fig. 2B. (C-D) Fungiform papillae in $\mathrm{BDNF}^{-/-}$mice are smaller than in wild-type mice. There are fewer PGP positive nerve fibers in the $\mathrm{BDNF}^{-/-}$fungiform papillae compared to wild-type mice. (E-H) The few remaining dorsal surface fungiform papillae in $\mathrm{BDNF}^{-/-} x \mathrm{NT}-3^{-/-}$ mice are small and receive scarce innervation. There are no innervated structures or areas in the papillae that resemble the intragemmal and perigemmal innervation patterns in these papillae as seen in wild-type papillae (compare to Fig. 2A and B). No PGT-positive taste cells are observed in the fungiform papillae in Fig. 2E-H. of fungiform papillae was distorted and the peri- and intragemmal innervation components were not recognizable and the pattern of innervation was different from that in wild-type mice. The number of fungiform papillae was reduced (Fig. 4A) and was only $62 \%$ of the number in wild-type mice $(38 \%$ reduction). Fungiform papillae were not observed posterior to the intermolar eminence. The papillae were smaller $(29 \mu \mathrm{m} \pm 0.6 \mathrm{SEM}$, see also Figs. 2A and B, and 4B) than in wild-type mice. In $\mathrm{BDNF}^{-1-} x \mathrm{NT}^{-3^{-/-}}$mice, there was a severe loss of fungiform papillae (Figs. 1B and $4 \mathrm{~A}$ ), and therefore possibly a subsequent loss of fungiform taste buds; the number of fungiform papillae was $15 \%$ of that in wild-type mice $(85 \%$ reduction). Fungiform papillae in $\mathrm{BDNF}^{-1-} x \mathrm{NT}^{-} 3^{-/-}$mice contained few nerve fibers (Fig. 2E-H) and were significantly smaller $(22 \mu \mathrm{m} \pm 0.4$ SEM, see also Fig. $4 \mathrm{~B})$ than both wild-type and $\mathrm{BDNF}^{-/-}$mice. The peri- and intragemmal innervation patterns were morphologically indistinguishable. We did not observe any PGPpositive taste cells and/or taste buds in $\mathrm{BDNF}^{-1-} x \mathrm{NT}$ $3^{-1-}$ mice.

\section{CIRCUMVALLATE PAPILLAE}

In wild-type mice, circumvallate papillae were welldeveloped (Fig. 1C) and richly innervated (Fig. 3A and B). There was a large subepithelial nerve plexus in the core part of the papillae, and a large number of intraepithelial nerve fibers extended into the epithelium (arrows in Fig. 3A and B) from the subepithelial nerve plexus (Fig. 3A and B). Many well-innervated taste buds were found embedded in the top surface and trench wall epithelia (arrowheads in Fig. 3A and B). Circumvallate papillae in $\mathrm{BDNF}^{-/-}$mice were smaller and contained fewer nerve fibers (Figs. 3 C and D, and Fig. 4C).

There were fewer intraepithelial nerve fibers in the vallate epithelium (arrowheads in Fig. 3C and D) and the subepithelial nerve plexus was reduced in size. In $\mathrm{BDNF}^{-/-} x \mathrm{NT}^{-} 3^{-/-}$mice, circumvallate papillae appeared underdeveloped (Fig. 1D) compared to wildtype mice (Fig. 1C). The papillae had a distorted morphology and were significantly smaller in size than wild-type mice (Fig. 4C). The trenches were shorter in depth than in wild-type mice. There were no PGPpositive taste cells and/or taste buds present in the vallate epithelium, and interestingly, no intraepithelial fibers were observed in the epithelium (Fig. 3E and F, arrows mark the areas of the trench and top surface epithelium). The subepithelial nerve plexus was reduced in size (Fig. 3E and F).

\section{ANTERIOR TONGUE}

The anterior tongue is well-innervated in wild-type mice and nerve fibers are found throughout the 

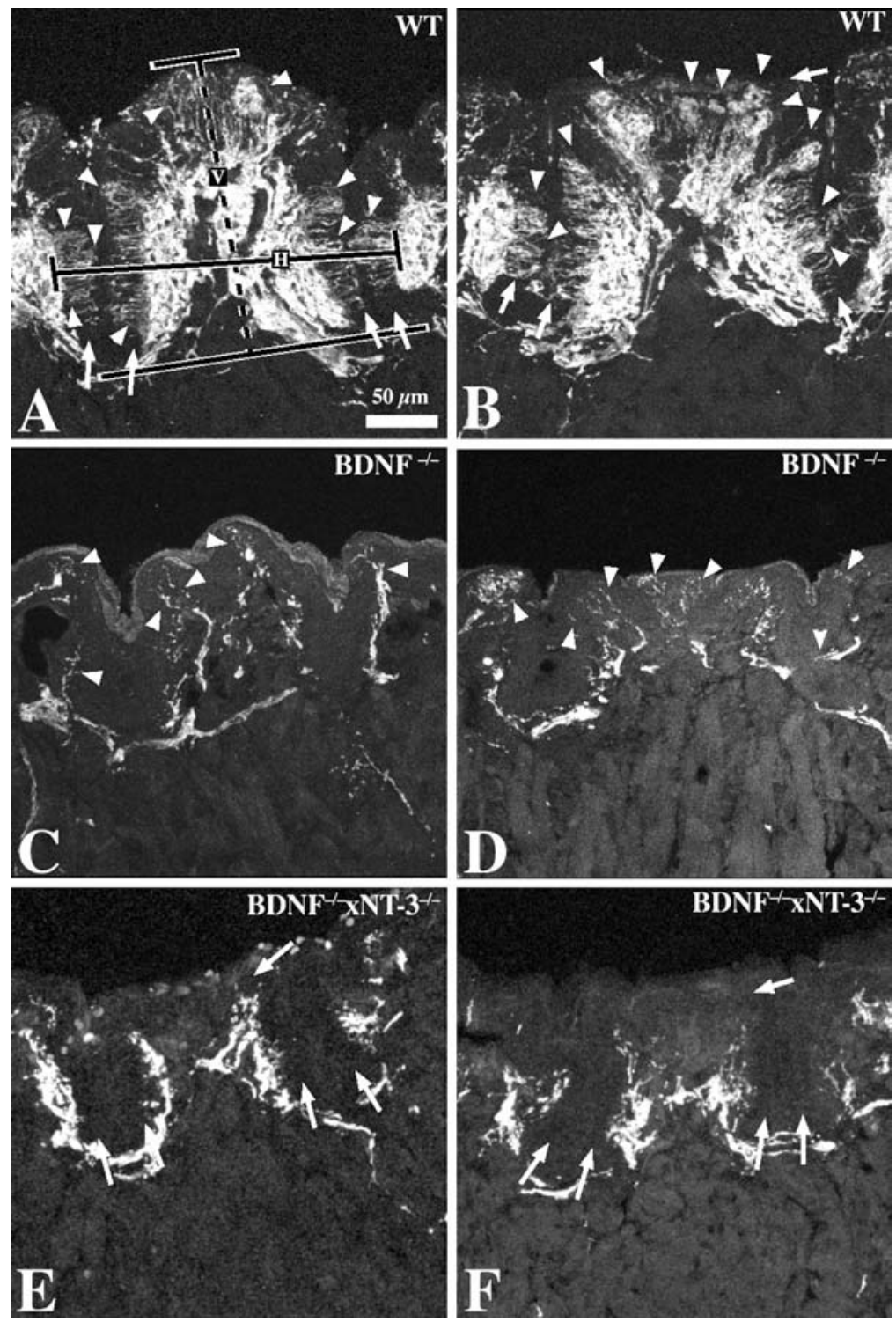

Fig. 3. (A-F) Protein gene product 9.5 (PGP) immunoreactivity in circumvallate papillae of wild-type (A and $\mathrm{B}), \mathrm{BDNF}^{-/-}(\mathrm{C}$ and $\mathrm{D})$ and $\mathrm{BDNF}^{-/-} x \mathrm{NT}-3^{-/-}(\mathrm{E}$ and $\mathrm{F})$ mice. Scale bar in $\mathrm{F}$ represents $50 \mu \mathrm{m}$ and applies to all figures. Circumvallate papillae are sectioned at same levels (midway anterior-posterior). (A and B) Circumvallate papillae are richly innervated in newborn wild-type mice and many taste buds (arrowheads) and intraepithelial nerve fibers are observed. Many taste buds are observed in the vallate top surface and trench wall epithelia. Note that there are many fine intraepithelial nerve fibers. The inner and outer trench wall epithelia are marked with arrows in 3A and B. Lines $\mathrm{V}$ and $\mathrm{H}$ represent the vertical and horizontal dimensions of each papilla that were used to measure the relative sizes of the papillae. The horizontal measure $(\mathrm{H})$ is the distance between two points on each side of the papilla on the basal lamina of the outer trench epithelium. The vertical dimension (V) is the distance between the highest point on the top surface epithelium to a line connecting the bottom of the trenches to each other. (C and D) Circumvallate papillae are smaller in BDNF knockout mice and the total amount of nerve fibers in the papillae is reduced. No taste buds are observed in these figures, and there are few intraepithelial nerve fibers. The subepithelial nerve plexus is reduced in size compared to wild-type mice. (E and F) Circumvallate papillae have a distorted morphology in $\mathrm{BDNF}^{-/-} x \mathrm{NT}^{-3^{-/-}}$mice. The papillae are smaller in size than in both BDNF knockout and wild-type mice and the trench is shorter in length. There are no PGP-positive taste cells present in the vallate epithelium. Interestingly, there are no intraepithelial fibers in the epithelium. The subepithelial nerve plexus is reduced in size.

tongue subepithelially (Fig. 5A) and are presumably somatosensory nerve fibers. The amount of subepithelial nerve fibers did not change in $\mathrm{BDNF}^{-/-}$mice (not shown). However there was a reduction in the amount of nerve fibers in the subepithelial plexus in $\mathrm{BDNF}^{-/-} x \mathrm{NT}^{-3^{-/-}}$mice (Fig. 5B). This loss is clearly shown in Fig. 5. We have previously reported a similar reduction of the nerve fibers in the subepithelial nerve 

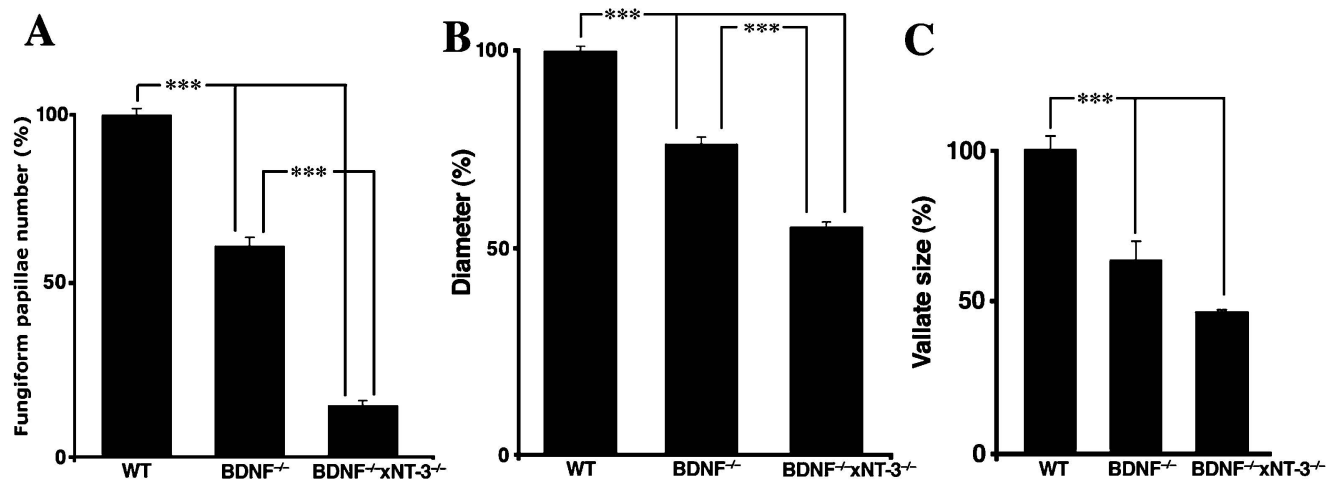

Relative number of fungiform papillae

Relative fungiform papillae diameter

Relative circumvallate papillae size

Fig. 4. Percentage changes in the relative number of fungiform papillae (A), diameter of the fungiform papillae (B), and size of the circumvallate papillae (C) in wild-type, $\mathrm{BDNF}^{-/-}$and $\mathrm{BDNF}^{-/-} x \mathrm{NT}^{-3^{-/}}$mice.
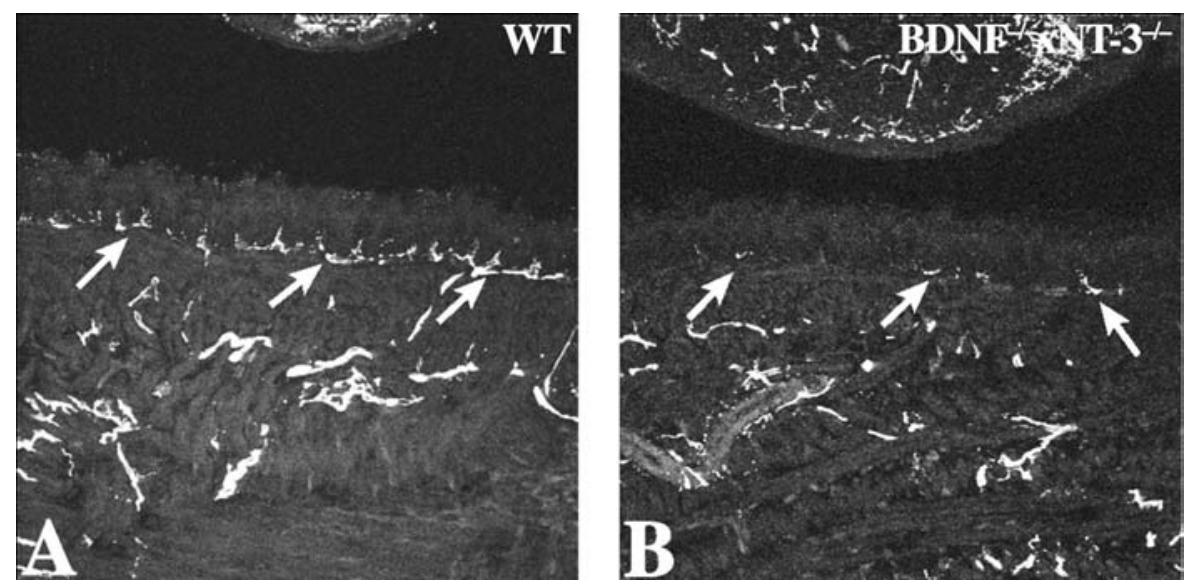

Fig. 5. Protein gene product 9.5 (PGP) immunoreactivity in the anterior tongue of wild-type (A) and $\mathrm{BDNF}^{-/-} x \mathrm{NT}^{-3^{-/-}}(\mathrm{B})$ mice. Anterior tongue shown here is devoid of fungiform papillae. Note that there are only few nerve fibers found in the subepithelial nerve plexus (arrows) in the double knockout mice compared to wild-type mice.

plexus in single NT-3 knockout mice (Nosrat et al., 1997).

\section{Discussion}

Specific gustatory deficits observed in single neurotrophin knockout mice are dependent on the specific loss of that neurotrophin (i.e., a consequence to the loss and/or possible developmental adaptations to the null mutation of a particular neurotrophin gene). Thus, such deficits in double neurotrophin knockout mice would be additive only if different neurotrophins exert different functions and utilize different modes of action. Two candidate neurotrophins with distinct and different modes of action in the innervation of the tongue are BDNF and NT-3. In contrast, combinatorial gene deletion of neurotrophins with similar modes of action and function would therefore show subtle differences from the neurotrophin knockout phenotype that is most predominant (i.e. the phenotype is masked by the phenotype of the dominant neurotrophin). If so, this would indicate that the spatial and/or temporal expression of a neurotrophin regulates the neurotrophin responsive neurons. Two neurotrophins that exhibit rather similar defecits in the anterior tongue are BDNF and NT4. To test these hypotheses, we have generated mice with nullmutation in $b d n f$ and $n t-3$ or $b d n f$ and $n t-4$ genes. The present study analyzes the phenotype of the $\mathrm{BDNF}^{-/-} x \mathrm{NT}-3^{-/-}$mice. To understand the specific functions of BDNF and NT-3, and to study the interrelationship between gustatory and somatosensory nerves, the phenotype in $\mathrm{BDNF}^{-/-} x \mathrm{NT}^{-3^{-/-}}$mice was compared to both wild-type and $\mathrm{BDNF}^{-/-}$mice. $\mathrm{BDNF}^{-/-} x \mathrm{NT}^{-3^{-/-}}$mice show additive (somatosensory and gustatory) deficits indicating distinct and separate roles for either neurotrophin in the innervation of the tongue. There is a clear loss of gustatory innervation that is reflected in the loss/reduced size of gustatory papillae and taste buds. There is a loss of NT-3 dependent somatosensory innervation as seen in the subepithelial nerve plexus in the tongue. We did not observe any gustatory deficits in the single NT-3 mice (Nosrat et al., 1997). However, the unexpected severe loss of fungiform papillae and PGP-positive fungiform 
taste buds in $\mathrm{BDNF}^{-/-} x \mathrm{NT}^{-3^{-/-}}$mice compared to single BDNF null mice indicates a clear necessity for the presence of both gustatory and somatosensory nerve components for normal development of taste buds and fungiform papillae. The loss of taste buds and fungiform papillae is not a simple additive effect of the addition of the phenotypes in a single $\mathrm{BDNF}^{-/-}$and NT$3^{-/-}$since there are no gustatory deficits in single NT-3 knockout mice. This indicates that some of the functions of the NT-3 dependent somatosensory innervation are compensated by the presence of BDNF dependent gustatory nerve fibers in the gustatory papillae in NT-3 knockout mice.

The total loss of intraepithelial nerve fibers in circumvallate papillae is another interesting finding in the double knockout mice. While there are still some intraepithelial nerve fibers present in the circumvallate papillae of $\mathrm{BDNF}^{-1-}$ mice, the somatosensory and gustatory nerve fibers are lost in the circumvallate papillae of BDNF/NT-3 double knockouts. The remaining nerve fibers in the core part of the circumvallate and fungiform papillae could indicate that not all nerves in the gustatory papillae are gustatory or somatosensory. It is possible that contributions from the autonomic nervous system are found in the papillae and are involved in the innervation of the gustatory papillae. Indeed, two potent neurotrophic factors for the autonomic nervous system, glial cell-line-derived neurotrophic factor (GDNF) and neurturin (NTN) are expressed in the developing tongue (Nosrat, 1998) and their receptor components are found in the lingual ganglia that are scattered through the anterior portion of the tongue and in the Remak's ganglion in the circumvallate papillae (Nosrat, 1998). There is a recent report in which GDNF and one of its receptor components have been detected in gustatory papillae and taste buds using immunohistochemistry (Takeda et al., 2004). Farbman and Hellekant (1978) demonstrated that not all nerve fibers are lost from gustatory ganglia upon transection of the lingual nerve. These remaining nerve fibers are however lost upon superior cervical ganglionectomy. another possibility is that neurotrophic factors other than BDNF and NT-3 support the gustatory and somatosensory neurons. GDNF has been shown to elicit extensive neurite outgrowth from the geniculate ganglion (Rochlin et al., 2000).

We recently showed that there is no general mechanism with which different neurotrophins can substitute for the action exerted by another neurotrophin, and this seems to be dependent on the specific organ system rather than the neurotrophins themselves (Agerman et al., 2003). We generated transgenic mice in which $b d n f$ was replaced by $n t-3$, resulting in expression of NT-3 in areas where BDNF is normally produced. Our results clearly demonstrate that NT-3 can not substitute for the specific roles of BDNF in the gustatory system.
Interestingly, NT-3 appears to replace all of the functions of BDNF in the auditory system, while it only promotes neuronal survival in the vestibular system without restoring function (Agerman et al., 2003).

BDNF is the most potent neurotrophin for the gustatory system. BDNF is expressed in the developing and the adult human and rodent taste buds (Nosrat, 1998; Nosrat et al., 2000; Yee et al., 2003). BDNF is a synaptogenic factor for BDNF responsive gustatory and retinotectal nerve fibers (Ringstedt et al., 1999; Choi et al., 1998; Krimm et al., 2001). Gustatory ganglia express the receptors (trkB and p75) for BDNF (Ernfors et al., 1992; Nosrat et al., 1998; Cho \& Farbman, 1999), and BDNF and TrkB knockout mice exhibit deficits in their gustatory system (Zhang et al., 1997; Nosrat et al., 1997; Mistretta et al., 1999; Fritzsch et al., 1997). Neurotrophin 4 knockout mice exhibit deficits in their gustatory system in the anterior part of the tongue (Lieble et al.,1999). Several different mechanisms are involved in bringing specificity and selectivity to BDNF or NT-4 binding to their common high affinity receptor TrkB and its downstream activation (Segal, 2003), and the mechanisms that are involved in BDNF and NT-4 signaling in the taste system are under investigation in our laboratories.

It has been shown that NT-3 is expressed in the developing geniculate ganglion (Ernfors et al., 1992). The expression of NT-3 in cranial and somatic ganglia has been proposed to promote the survival of neurons and lack of NT-3 leads to premature differentiation of neuronal precursor cells (Farinas et al., 1996; Wilkinson et al., 1996). It is therefore plausible that lack of NT-3 is also contributing to the loss of additional gustatory neurons in the geniculate ganglion and leading to a more severe phenotype in $\mathrm{BDNF}^{-/-} x \mathrm{NT}^{-} 3^{-/-}$than in single BDNF knockout mice.

In summary, our findings demonstrate that BDNF and NT-3 have specific roles in the innervation of the tongue and its papillae. Both BDNF-dependent gustatory and NT-3-dependent somatosensory innervation components are required for taste bud and gustatory papillae innervation and development.

\section{Acknowledgment}

C.A.N. and I.V.N. would like to thank Dr. Albert Farbman for support, mentorship and friendship. Supported by National Institute on Deafness and Other Communication Disorders, NIH Grant DC7628-01 (to C.A.N.).

\section{References}

AGERMAN, K., HJERLING-LEFFLER, J., BLANCHARD, M. P., SCARFONE, E., CANLON, B., NOSRAT, C. \& ERNFORS, P. (2003) BDNF gene replacement reveals multiple mechanisms for establishing neurotrophin 
specificity during sensory nervous system development. Development 130, 1479-1491.

BARLOW, L. A. \& NORTHCUTT, R. G. (1995) Embryonic origin of amphibian taste buds. Developmental Biology 169, 273-285.

CHO, T. T. \& FARBMAN, A. I. (1999) Neurotrophin receptors in the geniculate ganglion. Brain Research Molecular Brain Research 68, 1-13.

CHOI, S., YATES, P. A. \& O'LEARY, D. D. M. (1998) Localized BDNF application induces branch-like structures along retinal axons. Society of Neuroscience Abstract 24, 27.

ERNFORS, P., LEE, K. F. \& JAENISCH, R. (1994a) Mice lacking brain-derived neurotrophic factor develop with sensory deficits. Nature 368, 147-150.

ERNFORS, P., LEE, K. F., KUCERA, J. \& JAENISCH, R. (1994b) Lack of neurotrophin-3 leads to deficiencies in the peripheral nervous system and loss of limb proprioceptive afferents. Cell 77, 503-512.

ERNFORS, P., MERLIO, J. \& PERSSON, H. (1992) Cells expressing mRNA for neurotrophins and their receptors during embryonic rat development. European Journal of Neuroscience 4, 1140-1158.

ERNFORS, P., VANDEWATER, T., LORING, J. \& JAENISCH, R. (1995) Complementary roles of BDNF and NT-3 in vestibular and auditory development. Neuron 14, 1153-1164.

FAN, L., GIRNIUS, S. \& OAKLEY, B. (2004) Support of trigeminal sensory neurons by nonneuronal p75 neurotrophin receptors. Brain Research Developmental Brain Research 150, 23-39.

FARBMAN, A. I. (2003) Neurotrophins and taste buds. Journal of Comparative Neurology 459, 9-14.

FARBMAN, A. I. \& MBIENE, J. P. (1991) Early development and innervation of taste bud-bearing papillae on the rat tongue. Journal of Comparative Neurology 304, 172186.

FARINAS, I., YOSHIDA, C. K., BACKUS, C. \& REICHARDT, L. F. (1996) Lack of neurotrophin-3 results in death of spinal sensory neurons and premature differentiation of their precursors. Neuron 17, 1065-1078.

FRITZSCH, B., SARAI, P. A., BARBACID, M. \& SILOSSANTIAGO, I. (1997) Mice with a targeted disruption of the neurotrophin receptor trkB lose their gustatory ganglion cells early but do develop taste buds. International Journal of Developmental Neuroscience 15, 563-576.

GANCHROW, D., GANCHROW, J. R., VERDINALCAZAR, M. \& WHITEHEAD, M. C. (2003a) Brain-derived neurotrophic factor-, neurotrophin-3-, and tyrosine kinase receptor-like immunoreactivity in lingual taste bud fields of mature hamster. Journal of Comparative Neurology 455, 11-24.

GANCHROW, D., GANCHROW, J. R., VERDINALCAZAR, M. \& WHITEHEAD, M. C. (2003b) Brain-derived neurotrophic factor-, neurotrophin-3-, and tyrosine kinase receptor-like immunoreactivity in lingual taste bud fields of mature hamster after sensory denervation. Journal of Comparative Neurology 455, 25-39.

HÖUKFELT, T., FUXE, K., GOLDSTEIN, M. \& JOH, T. H. (1973) Immunohistochemical localization of three catecholamine synthesizing enzymes: aspects on methodology. Histochemie 33, 231-254.
KRIMM, R. F., MILLER, K. K., KITZMAN, P. H., DAVIS, B. M. \& ALBERS, K. M. (2001) Epithelial overexpression of BDNF or NT4 disrupts targeting of taste neurons that innervate the anterior tongue. Developmental Biology 232, 508-521.

LIEBL, D. J., MBIENE, J. P. \& PARADA, L. F. (1999) NT4/ 5 mutant mice have deficiency in gustatory papillae and taste bud formation. Developmental Biology 213, 378389.

LINDEMANN, B. (2001) Receptors and transduction in taste. Nature 413, 219-225.

MBIENE, J. P., MACCALlUM, D. K. \& MistRetTA, C. M. (1997) Organ cultures of embryonic rat tongue support tongue and gustatory papilla morphogenesis in vitro without intact sensory ganglia. Journal of Comparative Neurology 377, 324-340.

MISTRETTA, C. M., GOOSENS, K. A., FARINAS, I. \& REICHARDT, L. F. (1999) Alterations in size, number, and morphology of gustatory papillae and taste buds in BDNF null mutant mice demonstrate neural dependence of developing taste organs. Journal of Comparative Neurology 409, 13-24.

MistretTA, C. M., LIU, H. X., GAFFIELD, W. \& MACCALLUM, D. K. (2003) Cyclopamine and jervine in embryonic rat tongue cultures demonstrate a role for Shh signaling in taste papilla development and patterning: fungiform papillae double in number and form in novel locations in dorsal lingual epithelium. Developmental Biology 254, 1-18.

NOSRAT, C. A. (1998) Neurotrophic factors in the tongue; expression patterns, biological activity, relation to innervation and studies of neurotrophin knockout mice. Annals of the New York Academy of Science 855, 2850.

NOSRAT, C. A., BLOMLÖF, J., ELSHAMY, W. M., ERNFORS, P. \& OLSON, L. (1997) Lingual deficits in BDNF and NT3 mutant mice leading to gustatory and somatosensory disturbances, respectively. Development 124, 1333-1342.

NOSRAT, C. A., EBENDAL, T. \& OLSON, L. (1996) Differential expression of brain-derived neurotrophic factor and neurotrophin $3 \mathrm{mRNA}$ in lingual papillae and taste buds indicates roles in gustatory and somatosensory innervation. Journal of Comparative Neurology 376, 587602.

NOSRAT, C. A., FRIED, K., EBENDAL, T. \& OLSON, L. (1998) NGF, BDNF, NT-3, NT-4 and GDNF in tooth development. European Journal of Oral Sciences 106, 9499.

NOSRAT, C. A. \& OLSON, L. (1995) Brain-derived neurotrophic factor mRNA is expressed in the developing taste bud-bearing tongue papillae of rat. Journal of Comparative Neurology 360, 698704.

NOSRAT, C. A. \& OLSON, L. (1998) Changes in neurotrophin 3 mRNA expression patterns in the prenatal rat tongue suggest guidance of developing somatosensory nerves to their final targets. Cell Tissue Research 292, 619-623.

NOSRAT, I. V., LINDSKOG, S., SEIGER, Å. \& NOSRAT, C. A. (2000) Lingual BDNF and NT-3 mRNA expression patterns and their relation to innervation in the 
human tongue: similarities and differences compared with rodents. Journal of Comparative Neurology 417, 133152.

RINGSTEDT, T., IBÁÑTEZ, C. F. \& NOSRAT, C. A. (1999) Role of BDNF in target invasion in the gustatory system. Journal of Neuroscience 19, 3507-3518.

ROCHLIN, M. W., O'CONNOR, R., GIGER, R. J., VERHAAGEN, J. \& FARBMAN, A. I. (2000) Comparison of neurotrophin and repellent sensitivities of early embryonic geniculate and trigeminal axons. Journal of Comparative Neurology 422, 579-593.

SEGAL, R. A. (2003) Selectivity in Neurotrophin Signaling: Theme and Variations. Annual Reviews in Neuroscience 18, 18.

STONE, L. M., FINGER, T. E., TAM, P. \& TAN, S. S. (1995) Taste receptor cells arise from local epithelium, not neurogenic ectoderm. Proceedings of the National Academy of Sciences USA 92, 1916-1920.

TAKEDA, M., SUZUKI, Y., OBARA, N., UCHIDA, N. \& KAWAKOSHI, K. (2004) Expression of GDNF and GFR alpha 1 in mouse taste bud cells. Journal of Comparative Neurology 479, 94-102.

UCHIDA, N., KANAZAWA, M., SUZUKI, Y. \& TAKEDA, M. (2003) Expression of BDNF and TrkB in mouse taste buds after denervation and in circumvallate papillae during development. Archives of Histology and Cytology 66, $17-25$.

WILKINSON, G. A., FARINAS, I., BACKUS, C., YOSHIDA, C. K. \& REICHARDT, L. F. (1996) Neurotrophin-3 is a survival factor in vivo for early mouse trigeminal neurons. Journal of Neuroscience 16, 7661-7669.

YEE, C. L., JONES, K. R. \& FINGER, T. E. (2003) Brainderived neurotrophic factor is present in adult mouse taste cells with synapses. Journal of Comparative Neurology $459,15-24$.

ZHANG, C. X., BRANDEMIHL, A., LAU, D., LAWTON, A. \& OAKLEY, B. (1997) BDNF is required for the normal development of taste neurons in vivo. Neuroreport 8 , 1013-1017. 